\title{
Fecal microbiota transplantation for severe clostridium difficile infection after left ventricular assist device implantation: a case control study and concise review on the local and regional therapies
}

\author{
Zeina Z. Berro', Righab H. Hamdan², Israa H. Dandache', Mohamad N. Saab³, Hussein H. Karnib ${ }^{4}$ \\ and Mahmoud $\mathrm{H}$. Younes ${ }^{4^{*}}$
}

\begin{abstract}
Background: We report herein a case of fecal microbiota transplantation (FMT) used for severe Clostridium difficile infection for a 65-year-old Lebanese man who underwent left ventricular assist device implantation. To the best of our knowledge this is the first case report from Lebanon and the region presenting such technique.

Case presentation: The patient experienced diarrhea and rectal bleeding and was diagnosed of pseudomembranous colitis (PMC). His condition failed to improve on maximal pharmacological therapy. Protocolectomy, an invasive operation consisting in resection of the entire colon and rectum seemed to be the last resort before the patient responded to FMT given through gastroscopy.
\end{abstract}

Conclusion: Despite the increasing experience with FMT for $C$. difficile infection, published evidence in severe related cases from this region is very limited. Hence, we promote adjunctive FMT, an effective noninvasive method, to be considered as a promising early treatment option in severe C. difficile infection.

Keywords: Severe Clostridium difficile, Left ventricular assist device implantation ${ }_{2}$, Fecal microbiota transplantation ${ }_{3}$, Pseudomembranous colitis 4 , Therapy 5

\section{Background}

Clostridium difficile, a ubiquitous spore-forming Gram positive anaerobic bacillus, is the leading cause of antibiotic associated colitis which is among the most common infections implicated in increased-stay, morbidity and mortality of hospitalized patients [1, 2]. Inflammation, apoptosis and necrosis of intestinal cells are attributed to the disruption of the intestinal microbial equilibrium, which opens the floor for C. difficile to colonize and produce potent enterotoxins and cytotoxins [3]. Over the past few years, there has been an increasing emergence of the hypervirulent and hyperepidemic strain NAP1/B1/027 resulting in severe outbreaks and

\footnotetext{
* Correspondence: myouness55@yahoo.com

${ }^{4}$ Medical Research Center, Al Rassoul Al Aazam Hospital, Beirut, Lebanon Full list of author information is available at the end of the article
}

causing nosocomial infectious diarrhea [4-7]. The European C. difficile infection study (ECDIS) findings show that one in 10 cases of C. difficile infection is either transferred to intensive care unit, or necessitates colectomy, or dies [2]. Several antimicrobial treatment including metronidazole and vancomycin are approved for clinical use and are still recommended by many studies as the treatment of choice for serious infections [1]. Recently, with the recurrence and failure of classical treatments, new therapeutic strategies became available such as the novel US Food and Drug Administration (FDA) approved antimicrobial agent fidaxomicin, immunoglobulins and toxin chelators (e.g., cholestyramine, colestipol, tolevamer) along with a reevaluation of the conventional treatments with new recommendations for their use 
[5]. Another reported optional treatment for severe C. difficile is FMT, which constitutes restoration of the microbial flora in the lower gastrointestinal tract through the instilment of feces from healthy donors [8-10]. Although there is supporting evidence from different studies proving successful symptomatic resolution within $24 \mathrm{~h}$ of the procedure, the infectious diseases society of America (IDSA) and the European society of clinical microbiology and infectious diseases (ESCMID) guidelines concerning FMT recommends that it should be considered only when there is recurrence and failure of antibiotic therapy $[3,11,12]$. Few studies indicate a potential therapeutic role for FMT in extraintestinal disorders correlated with gut microbiota, such as cardiovascular disease, multiple sclerosis, colorectal cancer and others [13, 14]. Our manuscript describes a FMT case, performed against severe $C$. difficile infection for an open heart surgery patient who underwent left ventricular assist device implantation (LVAD). This is the first case report from Lebanon and the region presenting such technique. Altogether, FMT holds promise for reducing antibiotic use and expanding its clinical indications [13].

\section{Case presentation}

December 2014, a 65-year-old Lebanese male patient known to have severe ischemic cardiomyopathy with left ventricular dysfunction, type II diabetes, hypertension, and chronic moderate renal impairment, was transferred to our cardiac surveillance unit at the Beirut Cardiac Institute (BCI) medical center of $\mathrm{Al}$ Rassoul $\mathrm{Al}$ Aazam Hospital (RAH) for heart failure management. This tertiary health care center is a community based hospital, located in south Beirut in Lebanon and comprised of 2 community medical centers with a total of 260 beds.

Three months prior to his current admission, the patient had been diagnosed of single vessel coronary disease, which was managed in a peripheral hospital by an angioplasty with drug eluting stent implantation to the left anterior descending artery (LAD). He was then rehospitalized 2 weeks prior to his transfer to our center, in the same peripheral hospital, for acute myocardial infarction and cardiogenic shock. Urgent coronary angiogram showed occlusion of the LAD stent, the other arteries were unremarkable. Thus the patient underwent stent desobstruction, but despite such management his hemodynamics and left ventricular function did not improve, with failure to wean from inotropes. He was then referred to our center.

Upon his admission, the clinical exam revealed hypotension (mean arterial pressure: $65 \mathrm{mmHg}$ ), sinus tachycardia $(90 / \mathrm{min})$, cold extremities, pulmonary crackles, and hepatomegaly $(19.3 \mathrm{~cm})$. Electrocardiogram showed diffuse $\mathrm{Q}$ waves and $\mathrm{T}$ waves inversion in anterior leads; troponin level was high $(1.13 \mathrm{ng} / \mathrm{ml}$; normal range: 0-0.014) and blood test showed elevated creatinine $(1.45 \mathrm{mg} / \mathrm{dl}$; normal range: 0.6-1.3). Cardiac ultrasound showed a dilated left ventricle with extensive antero septo apical akinesia and a very low left ventricle ejection fraction (LVEF: $15 \%$ ). Chest X-ray showed subacute pulmonary oedema. We maintained the inotropes (Dobutamine), and we inserted an Intra Aortic balloon pump (IABP) on his second day of admission, allowing stabilization of hemodynamics and improvement of diuresis and renal function. Due to the failure of IABP weaning we performed a HeartWare left ventricular assist device (HeartWare, USA) on day 12. Intravenous (IV) vancomycin therapy was started empirically three days preoperatively (pre-op) and continued post-operatively (post-op) along with imipenem/cilastatin (IV) as infection prophylaxis. The patient was stable initially, with no surgery related complications. On day 4 postop he developed worsening of his kidney function with creatinine level reaching $2.37(\mathrm{mg} / \mathrm{dl})$. Vancomycin therapy was stopped. By day 12 post-op creatinine level decreased $(1.46 \mathrm{mg} / \mathrm{dl})$. Nevertheless, the patient had high white blood cells count $(30.3 \mathrm{k} / \mu \mathrm{L}$; normal range: 4-11) (Fig. 1); based on empirical evidence Acinetobacter baumannii was suspected and he was managed with teicoplanin, anidulafungin and polymyxin E along with imipenem/cilastatin.

By day 14 post-op he developed diarrhea and rectorrhagia (rectal bleeding) and laboratory testing indicated negative results for $\mathrm{C}$. difficile antigen. Abdomen and pelvis Computed tomography $(\mathrm{CT})$ scan showed significant thickening of the whole colon and rectum with surrounding fat stranding, illustrating pancolitis which is usually unresponsive to medication and requires frequently surgery [15]. Oral vancomycin and metronidazole (500 mg PO QID) were administered and former medicines were sustained. Day 17 post-op, his WBC decreased but diarrhea persisted, C. difficile antigen remained negative; culture stool was negative for Salmonella and Shigella; Entamoeba histolytica cysts (not

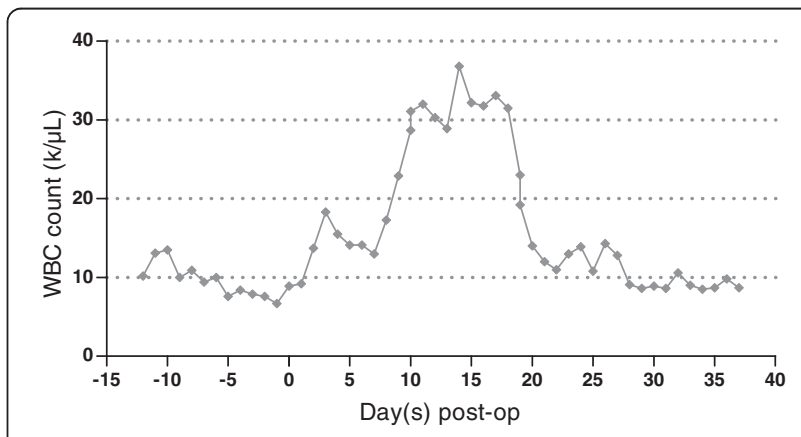

Fig. 1 White blood cells count (WBC) following LVAD open-heart surgery in a patient with severe pseumembranous colitis 
being the cause behind colitis) were seen in stool and occult blood was positive. He was continued on vancomycin and metronidazole, and started on oral rifaximin, ceftriaxone and probiotics (Euflora). Colonoscopy, performed on day 27 post-op, revealed diffuse colitis, scattered yellowish plaques and large amount of blood throughout the colon. A biopsy from the left colon was taken for histological diagnosis and reported benign colonic mucosa with marked thick layer of acute and chronic inflammatory cells that was most consistent with severe pseumembranous colitis. The patient was thus put on cholestyramine (Quantalan and Questran) regimen. The patient's condition worsened not responding to any of the conventional therapy. The gastroenterologist prescribed FMT prior to Protocolectomy. On day 32 post-op, FMT $(240 \mathrm{cc})$ was delivered, following the local hospital protocol into the duodenum through gastroscopy; an unrelated healthy person was the donor after proper stool testing for common pathogens. The patient's diarrhea improved within few hours and clinical resolution occurred after $24 \mathrm{~h}$.

\section{Conclusions}

We describe a case of severe $C$. difficile-associated diarrhea in an advanced heart failure patient who underwent LVAD surgery at our institution and was successfully treated with FMT, a technique used for the eradication of C. difficile-diarrhea, which gained much attention recently and proved to be more successful than other conventional treatments. To the best of our knowledge, this is the first local and regional description for FMT as being therapeutically efficient in hospitalized patients. Fecal microbiota transplantation was first described in 1958 for the treatment of pseudomembranous colitis [16], it consists primarily of restoring the normal intestinal flora. Several published cases from USA [17-19], Canada [20], United kingdom [21], China [22-24], Korea [25], Germany [26], Switzerland [27], Hungary [28], Italy [29], Denmark [30], Sweden [31], Norway [32], Romania [33], Finland [34], Australia [9, 35] and Czech Republic [36] have described performing FMT and getting good clinical outcomes. Case reports from France are very rare; in a review article, French authors explain that since there is no standardized procedure for FMT, the matter of considering it strictly in investigational clinical setting must be raised despite its increasing medical interest [37].

Unfortunately, there are minimal studies from the Middle Eastern countries informing about the incidence or the microbiological characteristics of $\mathrm{C}$. difficile strains [2]. To date, there have been no reports from the same region describing or recommending the use of FMT as a treatment for severe $C$. difficile infection, instead conventional therapies are employed and surgical procedures are used as a last resort.
Published article, from a Lebanese university hospital, recommended probiotics as prophylactic agents against antibiotics-associated diarrhea [38]. El-Herte et al. from Lebanon reported a case of metronidazole and vancomycin resistant $C$. difficile treated by a combination of rifamixin and tigecycline after the refusal of the patient to undergo surgical procedure [1]. Conversely caution with the use of tigecycline was urged in a Greek case report after its failure to treat a severe Clostridium infection in Intensive care unit (ICU) setting [39]. We point out here, that our patient didn't receive tigecycline due to shortage from medical suppliers during his illness period. A case study from Turkey treated successfully a patient, with end-stage renal disease, having $C$. difficileassociated diarrhea with metronidazole regimen for ten days; justifying their findings about the culture-negative peritonitis by the recent antibiotic therapy, and recommending the consideration of $C$. difficile in patients with culture-negative diarrhea [40]. From Iran, Goudarzi et $a l$. have investigated the susceptibility pattern of $C$. difficile clinical isolates and recommended as well metronidazole and vancomycin as first choice drugs for treatment [41]. Also from Iran Sadeghifard et al. recorded susceptibility of $C$. difficile to chloramphenicol and ceftriaxone [42]. Jordanian authors detected the genetic pattern of the $C$. difficile's toxins among hospitalized patients indicating as well susceptibility towards metronidazole and vancomycin [43]. Similar susceptibility studies were done in Kuwait and Saudi Arabia describing antibiotic resistances without proposing any potential solutions [44, 45]; just one report by Abdulaziz et al. informed about the use of intravenous immunoglobulin as adjuvant to antibiotics ensuing with successful outcome [46]. Hospitals in Quatar as well continue on using conventional treatments even for severe cases of C. difficile [47, 48]. Published data from Israel reported and recommended the use of conventional antibiotics [49-51] as successful therapy against $C$. difficile. However, despite such guidelines from their country, a recent study from Israel in collaboration with Boston, USA developed frozen FMT capsules for patients with recurrent $C$. difficile infection, and evaluated the safety and effectiveness of such administration [52]. This might open a solution for the standardization of the FMT procedure. We tried to order FMT capsules for our patient, but there were some restrictions from the suppliers' side, since they require from patients willing to try this treatment to be administered and followed directly by USA providers for investigational purposes.

FMT preparation following the local hospital protocol successfully resolved our patient's symptoms without recourse to surgery. In conclusion, we recommend fecal microbiota transplantation, for severe forms of C. difficile infection, as the best option for treatment. 


\section{Abbreviations}

$\mathrm{BCl}$, Beirut Cardiac Institute; CT, computed tomography; ECDIS, European C. difficile infection study; ESCMID, European society of clinical microbiology and infectious diseases; FDA, Food and Drug Administration; FMT, fecal microbiota transplantation; IABP, intra Aortic balloon pump; ICU, intensive care unit; IDSA, infectious diseases society of America; LAD, left anterior descending artery; LVEF, left ventricle ejection fraction; PMC, pseudomembranous colitis; RAH, Al Rassoul Al Aazam Hospital.

\section{Acknowledgments}

The authors thank the research committee of Al Rassoul Al Aazam Hospital.

\section{Funding}

No funding was obtained for this study.

\section{Availability of data and materials}

Data will not be shared, because identifying/confidential patient data shouldn't for ethical reasons.

\section{Authors' contributions}

All the authors have contributed to this manuscript. Dr. ZZB M.D. has performed the Fecal Microbiota Transplantation and helped in correcting the manuscript. Dr. RHH M.D. has followed the cardiac status of the patient and helped in correcting the manuscript. Dr. IHD Ph.D. has contributed to the literature review and manuscript redaction. Dr. MNS M.D. has performed the cardiac surgery. Drs. HHK M.D. and MHY M.D. have helped in writing and correcting the manuscript. We confirm that all authors have read and approved the final version of the manuscript.

\section{Competing interests}

The authors declare that they have no competing interests.

\section{Consent}

Written informed consent was obtained from the patient for publication of this Case report and any accompanying images. A copy of the written consent is available for review by the Editor of this journal.

\section{Ethical considerations}

The current case report was approved for publication by the Institutiona Review Board of RAH, and the patient data used in this study was anonymized. The study was conducted in accordance with the Declaration of Helsinki.

\section{Author details}

'Gastroentorology Department, Al Rassoul Al Aazam Hospital, Beirut, Lebanon. ${ }^{2}$ Cardiology Department, Beirut Cardiac Institute, Beirut, Lebanon. ${ }^{3}$ Cardiothoracic Surgery Department, Beirut Cardiac Institute, Beirut, Lebanon. ${ }^{4}$ Medical Research Center, Al Rassoul Al Aazam Hospital, Beirut, Lebanon.

Received: 28 September 2015 Accepted: 17 May 2016 Published online: 27 May 2016

\section{References}

1. El-Herte RI, Baban TA, Kanj SS. Recurrent refractory Clostridium difficile colitis treated successfully with rifaximin and tigecycline: a case report and review of the literature. Scand J Infect Dis. 2012;44(3):228-30.

2. Le Monnier A, Zahar JR, Barbut F. Update on Clostridium difficile infections. Med Mal Infect. 2014:44(8):354-65.

3. Nitzan O, Elias M, Chazan B, Raz R, Saliba W. Clostridium difficile and inflammatory bowel disease: role in pathogenesis and implications in treatment. World J Gastroenterol. 2013;19(43):7577-85.

4. Vonberg RP, Kuijper EJ, Wilcox MH, Barbut F, Tull P, Gastmeier P, et al Infection control measures to limit the spread of Clostridium difficile. Clin Microbiol Infect. 2008;14 Suppl 5:2-20.

5. Dinh A, Bouchand F, Le Monnier A. [Current treatment and epidemiology of Clostridium difficile infections]. Rev Med Interne. 2015;36(9):596-602.

6. Loo VG, Poirier L, Miller MA, Oughton M, Libman MD, Michaud S, et al. A predominantly clonal multi-institutional outbreak of Clostridium difficileassociated diarrhea with high morbidity and mortality. N Engl J Med. 2005 353(23):2442-9.
7. Stabler RA, Dawson LF, Phua LT, Wren BW. Comparative analysis of BI/NAP1/ 027 hypervirulent strains reveals novel toxin B-encoding gene (tcdB) sequences. J Med Microbiol. 2008;57(Pt 6):771-5.

8. Gordon H, Harbord M. A patient with severe Crohn's colitis responds to Faecal Microbiota Transplantation. J Crohns Colitis. 2014;8(3):256-7.

9. Trubiano JA, Gardiner B, Kwong JC, Ward P, Testro AG, Charles PG. Faecal microbiota transplantation for severe Clostridium difficile infection in the intensive care unit. Eur J Gastroenterol Hepatol. 2013;25(2):255-7.

10. Goudarzi M, Seyedjavadi SS, Goudarzi H, Mehdizadeh Aghdam E, Nazeri S. Clostridium difficile infection: epidemiology, pathogenesis, risk factors, and therapeutic options. Scientifica. 2014;2014:916826.

11. Cohen SH, Gerding DN, Johnson S, Kelly CP, Loo VG, McDonald LC, et al. Clinical practice guidelines for Clostridium difficile infection in adults: 2010 update by the society for healthcare epidemiology of America (SHEA) and the infectious diseases society of America (IDSA). Infect Control Hosp Epidemiol. 2010;31(5):431-55

12. Debast SB, Bauer MP, Kuijper EJ, European Society of Clinical M, Infectious $D$. European society of clinical microbiology and infectious diseases: update of the treatment guidance document for Clostridium difficile infection. Clin Microbiol Infect. 2014;20 Suppl 2:1-26.

13. Xu MQ, Cao HL, Wang WQ, Wang S, Cao XC, Yan F, et al. Fecal microbiota transplantation broadening its application beyond intestinal disorders. World J Gastroenterol. 2015;21(1):102-11.

14. Smits LP, Bouter KE, de Vos WM, Borody TJ, Nieuwdorp M. Therapeutic potential of fecal microbiota transplantation. Gastroenterology. 2013;145(5): 946-53.

15. Hanauer SB. Inflammatory bowel disease: epidemiology, pathogenesis, and therapeutic opportunities. Inflamm Bowel Dis. 2006;12 Suppl 1:S3-9.

16. Eiseman B, Silen W, Bascom GS, Kauvar AJ. Fecal enema as an adjunct in the treatment of pseudomembranous enterocolitis. Surgery. 1958:44(5):854-9.

17. Zainah H, Silverman A. Fecal bacteriotherapy: a case report in an immunosuppressed patient with ulcerative colitis and recurrent Clostridium difficile infection. Case Rep Infect Dis. 2012;2012:810943.

18. Russell G, Kaplan J, Ferraro M, Michelow IC. Fecal bacteriotherapy for relapsing Clostridium difficile infection in a child: a proposed treatment protocol. Pediatrics. 2010;126(1):e239-242.

19. Ray A, Smith R, Breaux J. Fecal microbiota transplantation for Clostridium difficile Infection: the Ochsner experience. Ochsner J. 2014;14(4):538-44.

20. Silverman MS, Davis I, Pillai DR. Success of self-administered home fecal transplantation for chronic Clostridium difficile infection. Clin Gastroenterol Hepatol. 2010;8(5):471-3.

21. Porter RJ, Fogg C. Faecal microbiota transplantation for Clostridium difficile infection in the United Kingdom. Clin Microbiol Infect. 2015;21(6):578-82.

22. Li Q, Wang C, Tang C, He Q, Zhao X, Li N, et al. Therapeutic modulation and reestablishment of the intestinal microbiota with fecal microbiota transplantation resolves sepsis and diarrhea in a patient. Am J Gastroenterol. 2014:109(11):1832-4.

23. Wang J, Xiao $Y$, Lin K, Song F, Ge T, Zhang T. Pediatric severe pseudomembranous enteritis treated with fecal microbiota transplantation in a 13-month-old infant. Biomed Rep. 2015;3(2):173-5

24. Li Q, Wang C, Tang C, He Q, Zhao X, Li N, et al. Successful treatment of severe sepsis and diarrhea after vagotomy utilizing fecal microbiota transplantation: a case report. Crit Care. 2015:19(1):738.

25. Gweon TG, Lee KJ, Kang DH, Park SS, Kim KH, Seong HJ, et al. A case of toxic megacolon caused by Clostridium difficile infection and treated with fecal microbiota transplantation. Gut Liver. 2015;9(2):247-50.

26. Ehlermann $\mathrm{P}$, Dosch AO, Katus HA. Donor fecal transfer for recurrent Clostridium difficile-associated diarrhea in heart transplantation. J Heart Lung Transplant. 2014;33(5):551-3.

27. Broecker F, Kube M, Klumpp J, Schuppler M, Biedermann L, Hecht J, et al. Analysis of the intestinal microbiome of a recovered Clostridium difficile patient after fecal transplantation. Digestion. 2013;88(4):243-51.

28. Nagy GG, Varvolgyi C, Paragh G. [Successful treatment of life-threatening, treatment resistant Clostridium difficile infection associated pseudomembranous colitis with faecal transplantation]. Orv Hetil. 2012; 153(52):2077-83.

29. Cammarota G, laniro G, Gasbarrini A, Masucci L, Sanguinetti M. Faecal transplantation for Clostridium difficile infection. Three cases treated in Italy. Dig Liver Dis. 2014;46(5):475.

30. Floe A, Leutscher P. Recurrent Clostridium difficile infection treated with faecal microbiota transplantation. Ugeskr Laeger. 2014;176(4):V04130223. 
31. Emanuelsson F, Claesson BE, Ljungstrom L, Tvede M, Ung KA. Faecal microbiota transplantation and bacteriotherapy for recurrent Clostridium difficile infection: a retrospective evaluation of 31 patients. Scand J Infect Dis. 2014;46(2):89-97.

32. Garborg K, Waagsbo B, Stallemo A, Matre J, Sundoy A. Results of faecal donor instillation therapy for recurrent Clostridium difficile-associated diarrhoea. Scand J Infect Dis. 2010;42(11-12):857-61.

33. Dumitru IM, Dumitru E, Resul G, Curtali L, Paris S, Rugina S. Concomitant CMV and Clostridium difficile colitis in an immunocompetent patient treated with Ganciclovir and fecal transplantation. J Gastrointestin Liver Dis. 2014:23(2):221-2.

34. Mattila E, Uusitalo-Seppala R, Wuorela M, Lehtola L, Nurmi H, Ristikankare M, et al. Fecal transplantation, through colonoscopy, is effective therapy for recurrent Clostridium difficile infection. Gastroenterology. 2012;142(3):490-6.

35. Borody TJ, Warren EF, Leis S, Surace R, Ashman O. Treatment of ulcerative colitis using fecal bacteriotherapy. J Clin Gastroenterol. 2003;37(1):42-7.

36. Polak P, Freibergerova M, Jurankova J, Kocourkova H, Mikesova L, Svacina R, et al. [First experiences with faecal bacteriotherapy in the treatment of relapsing pseudomembranous colitis due to Clostridium difficile]. Klin Mikrobiol Infekc Lek. 2011;17(6):214-7.

37. Barbut F, Collignon A, Butel MJ, Bourlioux P. Fecal microbiota transplantation: review. Ann Pharm Fr. 2015;73(1):13-21.

38. Issa I, Moucari R. Probiotics for antibiotic-associated diarrhea: do we have a verdict? World J Gastroenterol. 2014;20(47):17788-95.

39. Kopterides P, Papageorgiou C, Antoniadou A, Papadomichelakis E, Tsangaris I, Dimopoulou I, et al. Failure of tigecycline to treat severe Clostridium difficile infection. Anaesth Intensive Care. 2010;38(4):755-8.

40. Arikan T, Unal A, Kocyigit I, Yurci A, Oymak O. Peritoneal dialysis-related peritonitis triggered by Clostridium difficile-associated colitis. Perit Dial Int. 2014;34(1):139-40.

41. Goudarzi M, Goudarzi H, Alebouyeh M, Azimi Rad M, Shayegan Mehr FS, Zali MR, et al. Antimicrobial susceptibility of clostridium difficile clinical isolates in Iran. Iran Red Crescent Med J. 2013;15(8):704-11.

42. Sadeghifard N, Salari MH, Ghassemi MR, Eshraghi S, Amin Harati F. The incidence of nosocomial toxigenic clostridium difficile associated diarrhea in Tehran tertiary medical centers. Acta Med Iran. 2010;48(5):320-5.

43. Nasereddin LM, Bakri FG, Shehabi AA. Clostridium difficile infections among adult hospitalized patients. Am J Infect Control. 2009;37(10):864-6.

44. Jamal WY, Mokaddas EM, Verghese TL, Rotimi VO. In vitro activity of 15 antimicrobial agents against clinical isolates of Clostridium difficile in Kuwait. Int J Antimicrob Agents. 2002;20(4):270-4.

45. Al-Tawfiq JA, Momattin H, Al-Habboubi F, Dancer SJ. Restrictive reporting of selected antimicrobial susceptibilities influences clinical prescribing. J Infect Public Health. 2014;8(3):234-1. doi:10.1016/j.jph.2014.09.004.

46. Abdulaziz S, Abou-Shala N, Al-Tarifi A, Amin R. Salvage immunotherapy for fulminant pseudomembranous colitis. BMJ Case Rep. 2013, 2013.

47. Brooks JP, Perry WB, Richards ML. Abdominal distention and diarrhea in a young female. Curr Surg. 2004;61 (5):435-8.

48. Khan FY, Abu-Khattab M, Anand D, Baager K, Alaini A, Siddique MA, et al. Epidemiological features of Clostridium difficile infection among inpatients at Hamad General Hospital in the state of Qatar, 2006-2009. Travel Med Infect Dis. 2012;10(4):179-85.

49. Beloosesky Y, Grosman B, Marmelstein V, Grinblat J. Convulsions induced by metronidazole treatment for Clostridium difficile-associated disease in chronic renal failure. Am J Med Sci. 2000;319(5):338-9.

50. Martinelli M, Strisciuglio C, Veres G, Paerregaard A, Pavic AM, Aloi M, et al. Clostridium difficile and pediatric inflammatory bowel disease: a prospective, comparative, multicenter, ESPGHAN study. Inflamm Bowel Dis. 2014;20(12):2219-25.

51. Froom P. Commentary on "High frequency of nonadherence to Clostridium difficile treatment guidelines". South Med J. 2014;107(9):600-1.

52. Youngster I, Russell GH, Pindar C, Ziv-Baran T, Sauk J, Hohmann EL. Oral, capsulized, frozen fecal microbiota transplantation for relapsing Clostridium difficile infection. JAMA. 2014;312(17):1772-8.

\section{Submit your next manuscript to BioMed Central and we will help you at every step:}

- We accept pre-submission inquiries

- Our selector tool helps you to find the most relevant journal

- We provide round the clock customer support

- Convenient online submission

- Thorough peer review

- Inclusion in PubMed and all major indexing services

- Maximum visibility for your research

Submit your manuscript at www.biomedcentral.com/submit
() BioMed Central 